Д-р техн. наук В.Н. Остапчук

\title{
СОВЕРШЕНСТВОВАНИЕ ПРОЦЕССА ТЕРМОМЕХАНИЧЕСКОГО УПРОЧНЕНИЯ КОЛЕС ЦЕЛЬНОКАТАНЫХ
}

\begin{abstract}
Введение. Безопасность движения подвижного состава и экономическая эффективность грузоперевозок во многом зависят от эксплуатационной долговечности колесной пары, которая в большинстве случаев определяется контактно-усталостной прочностью и износостойкостью верхних слоев металла обода колеса и качеством ее ремонта.
\end{abstract}

\begin{abstract}
Постановка проблемы. При восстановление профиля колес повышенной твердости в настоящее время существуют две проблемы. Во-первых, это неудовлетворительное качество механической обработки колес с термомеханическими повреждениями, проявляющееся на поверхности катания после их обточки, в результате технологической наследственности,
\end{abstract}


макронеровностей, которые при дальнейшей эксплуатации колесной пары являются причиной возникновения дополнительных напряжений материала в пятне контакта системы «колесо-рельс» и образования выщербин, и как следствие, уменьшения пробега. Во-вторых, снятие в стружку значительного слоя полезного металла, что сокращает срок службы колеса. Кроме того, процесс восстановления профиля колес повышенной твердости характеризуется высокими затратами, обусловленными повышенным расходом твердосплавных режущих пластин, который в 3-5 раз выше расхода при восстановлении профиля стандартных вагонных колес. Режущие пластины разрушаются из-за ударных нагрузок, возникающих от термомеханических повреждений вагонных колес и превышающих предел прочности режущего инструмента. Таким образом, проблема продления срока службы колеса и снижение затрат на восстановительные работы является крайне актуальной.

Анализ последних исследований и публикаций. Как известно, цельнокатаные вагонные колеса на металлургических предприятиях изготавливают с использованием операций штамповки и прокатки. Затем после изотермической выдержки, охлаждения и механической обработки осуществляется термообработка колес, заключающаяся в упрочнении обода колеса. Технология термической обработки колес не регламентирует прокаливаемость, обеспечивая неравномерную, убывающую твердость по сечению обода. По данным работы [1] снижение твердости обода на одну единицу НВ в эксплуатационном интервале твердостей снижает его износостойкость примерно на один процент. То есть срезаемый слой металла обода при обточках не только уменьшает диаметр колеса, но и определяет снижение его износостойкости. Можно отметить два основных пути повышения ресурса колес при ремонте:
- за счет экономии металла обода, нерационально срезаемого при ремонте;

- увеличения износостойкости, в том числе оставшейся части рабочей толщины металла обода.

В настоящее время второй путь реализован частично. Появились железнодорожные колеса с повышенной твердостью обода до 320-360 HB на глубине 30 мм от поверхности катания. После начала их эксплуатации отмечено [2] сокращение контактно-усталостных повреждений обода в 4 раза и увеличение срока службы не менее чем в 1,5 раза. При сравнении с колесами по ГОСТ 10791-2011 количество отцепок вагонов (на 1000 ед.) в текущий отцепочный ремонт по дефектам колесных пар повышенной твердости почти в 2,5 раза меньше, чем по существующей технологии.

Одновременно возникает вопрос, связанный с особенностями восстановления профиля и обрабатываемостью колес повышенной твердости. Как показывает производственный опыт, расчетное определение режимов восстановления профиля поверхности катания колес связано со снижением уровня режимов резания и основного (машинного) времени, т. е. производительности. В таблице приведены расчетные данные [3] по режимам черновой обработки при восстановлении профиля поверхности катания колесных пар с разной твердостью.

Фактическим показателем производительности является минутная подача $\mathrm{S}$, мм/мин, которая, как видно из таблицы, для колес повышенной твердости меньше примерно в 2 раза по сравнению с данными показателями для колес по ГОСТ 10791-2011.

Следовательно, производительность современных колесотокарных станков, где машинное время составляет большую часть штучного, снизится примерно в 2 раза.

Цель работы состоит в повышении износостойкости колес цельнокатаных термомеханохимическим воздействием. 
Расчётные данные по режимам обработки

\begin{tabular}{|c|c|c|c|c|c|c|c|}
\hline \multicolumn{4}{|c|}{ ГОСТ 10791-2004 (285 HB) } & \multicolumn{4}{|c|}{ Ty 0943-157-01124328-2003 $(360 \mathrm{HB})$} \\
\hline t, & $\begin{array}{l}\text { S, } \\
\text { MM/ } 06\end{array}$ & $\begin{array}{l}\mathrm{n}, \\
06 / \mathrm{suH}\end{array}$ & $\begin{array}{l}\mathrm{S}_{\mathrm{M}} \\
\mathrm{MM} / \mathrm{MnH}\end{array}$ & t, & $\begin{array}{l}\text { S, } \\
\text { MM/ } 06\end{array}$ & $\begin{array}{l}\mathrm{n}, \\
06 / \mathrm{suн}\end{array}$ & $\begin{array}{l}\mathrm{S}_{\mathrm{M}}, \\
\mathrm{MM} / \mathrm{MuH}\end{array}$ \\
\hline 3 & 1,4 & $13 / 9$ & $18 / 12$ & 3 & 1,2 & $7 / 5$ & $8 / 5$ \\
\hline 5 & 1,2 & $12 / 8$ & $14 / 10$ & 5 & 1,0 & $7 / 5$ & $7 / 5$ \\
\hline 7 & 1,2 & $12 / 8$ & $14 / 10$ & 7 & 1,0 & $7 / 5$ & $7 / 5$ \\
\hline 9 & 1,2 & $12 / 8$ & $14 / 10$ & 9 & 1,0 & $7 / 5$ & $7 / 5$ \\
\hline
\end{tabular}

П р и м е ч а и и е : в знаменателе приведены данные для инструмента, которым обработаны 4-е колесные пары

Основной матеріал. Повышение производительности восстановления колесных пар повышенной твердости по профилю поверхности катания при ремонте можно обеспечить за счет других методов обработки, например комплексной поверхностной обработки, совмещающей технологию нанесения покрытий и термическую обработку в один технологический цикл. В результате такой обработки на поверхности колеса происходит не только изменение структуры поверхностного слоя, но и формируется покрытие, которое выполняет роль твердой смазки, защищающее рабочую поверхность от термомеханохимических воздействий. Покрытие, сформированное на поверхности колеса, выполняет роль твердой смазки и, как следствие, не происходит изменение его триботехнических свойств. В процессе формирования покрытия при комплексной обработке происходит заполнение неровностей и микротрещин после механической обработки поверхности стальных изделий, затем - диффузия химических элементов, которые находятся в растворе (хром, фосфор, кислород), с последующей хемосорбцией с образованием оксидов железа, хрома, фосфатов железа и ортофосфатов хрома. Поверхностный слой, полученный в результате такой обработки, состоит из нескольких слоев: верхний слой сформирован за счет элементов, находящихся в растворе, нижний слой, прилегающий к металлической основе за счет элементов матрицы и между первым и вторым слоем есть промежуточным слоем, который состоит из элементов как первого, так и второго слоя. Наличие переходного слоя обеспечивает повышение износостойкости деталей. Поверхностный слой со слоистой структурой, полученный по новой технологии, благодаря наличию прочных связей между атомами слоя в горизонтальной плоскости и более слабых в вертикальной, будет обеспечивать легкое скольжение тонких слоев друг по другу. В нашем случае процесс трения можем рассматривать как один из важнейших процессов структурной активации материала поверхностного слоя. Под действием механических сил будут протекать химические реакции между твердыми телами, участвующими в трении, либо реакции обмена одного или другого из этих компонентов окружающей их среды. Материал поверхностного слоя будет своеобразным катализатором, вызывающим или ускоряющим процессы обмена между компонентами окружающей среды. Работами многих ученых установлено, что важную роль при трении играет кислород. Так, опыты показали, что если на поверхности трения образуются оксиды, то это приводит к резкому снижению трения и износа. Длительное время считалось, что если поверхностный слой содержит 
фосфор, то он образует пленки фосфидов железа. Однако результаты экспериментальных исследований выявили более сложный характер взаимодействия. Исследования поверхностей трения железоуглеродистых сплавов, выполненные с помощью методов рентгеновской и электронной дифракции, обнаружили преимущественное наличие оксидов железа, хрома и фосфидов железа. При формировании пленок вторичных структур существенную роль играют окислительные процессы. Наличие кислорода не только в зоне трения, но и в самом слое способствует протеканию окислительных процессов (рисунок).

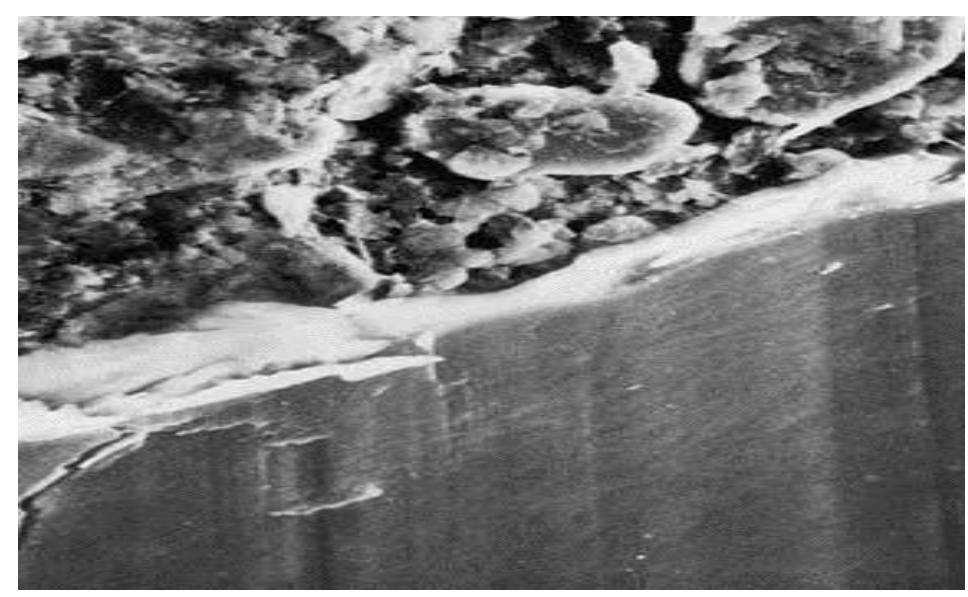

Рис. Поверхностный слой на сплаве

Под действием высоких давлений и сдвиговых деформаций мелкодисперсные частицы твердой смазки заполняют микронеровности поверхности и связываются с металлом на молекулярном уровне, образуя плотную защитную пленку. Она устраняет микродефекты поверхности, способствуя максимальному снижению коэффициента трения и температуры в зоне трения. Это способствует минимизации износа, окисления масла и обеспечению долговременной смазки. Электронографические исследования продуктов износа, образовавшихся при трении, позволили последовательно проследить за изменением их фазового состава во времени. В начальный период трения в продуктах износа преобладает фосфид железа, а также значительное количество свободного хрома. С увеличением времени в продуктах износа появляется феррофосфат железа. При установившихся условиях трения, характеризуемых минимальными в данных условиях испытаний коэффициентами трения и износом, на поверхностях трения формируются устойчивая пленка, представляющая собой моногидроокись $\delta-\mathrm{FeO}(\mathrm{OH})$, которая характеризуется наиболее плотно упакованными кристаллическими плоскостями параллельно направлению скольжения, и пленка фосфида железа, обладающая низкими антифрикционными показателями. Абсорбируясь на поверхности трения, продукты распада формируют граничный слой, улучшающий смазочное действие. Таким образом, фосфор содержащие поверхностные слои выполняют при трении двойную роль. С одной стороны, они обеспечивают образование фосфоросодержащих вторичных структур с повышенной поверхностной прочностью, а с другой - облегчают процессы распада продуктов износа с образованием моногидроокиси, оказывающей дополнительное смазочное действие. 
Выводы. Для увеличения ресурса эксплуатирующихся колес и сокращения потребностей транспорта в процессе ремонта целесообразно использовать экономичные способы восстановления.

\section{Список литературы}

1. Марков, Д.П. Трибология и ее применение на железнодорожном транспорте [Текст] / Д.П. Марков // Труды ВНИИЖТ. - М.: Интекст, 2007. - С. 205-211.

2. Торина, Я. Экономический эффект твердого колеса [Текст] / Я. Торина. - РЖДПАРТНЕР, 2009. - № 10(158) - С. 100 - 101.

3. Воробьев, А.А. Сравнение режимов обработки обода железнодорожных колес повышенной твердости по ГОСТ 10791 [Текст] / А.А. Воробьев, И.А. Иванов, В.С. Кушнер, С.В. Урушев // Конструкционно-технологическое обеспечение надежности колес рельсовых экипажей: сб. научн. трудов. - С.Пб.: ПГУПС, 2009. - С. 70-82.

Ключевые слова: термомеханическое упрочнение, комплексная обработка, покрытие, поверхностный слой.

\section{Аннотации}

Розглянуто причини руйнування коліс суцільнокатаних з підвищеною твердістю, а також способи їх усунення. Розглянуто методи відновлення профілю коліс із застосуванням комплексної поверхневої обробки, що поєднує технологію нанесення покриттів і термічну обробку в один технологічний цикл. Покриття, сформоване на поверхні колеса, виконує роль твердого мастила без зміни структури і властивостей.

Рассмотрены причины разрушения колес цельнокатаных с повышенной твердостью, а также способы их устранения. Рассмотрены методы восстановления профиля колес с применением комплексной поверхностной обработки, совмещающей технологию нанесения покрытий и термическую обработку в один технологический цикл. Покрытие, сформированное на поверхности колеса, выполняет роль твердой смазки без изменения структуры и свойств.

The reasons of the destruction of solid-rolled wheels with increased hardness and their solutions ways were considered in this work The methods of restoring wheels' profile with the application of complex surface treatment which combines the technology of coatings application and heat treatment in one technological cycle were considered. Coating which is formed on the wheel surface acts as a solid lubricant without changing its structure and properties. 